\title{
40 kW/L High Switching Frequency Three-Phase 400 Vac All-SiC Inverter
}

\author{
Kensuke Sasaki ${ }^{1,2, a}$, Shinji Sato ${ }^{1,3}$, Kohei Matsui ${ }^{1,4}$, Yoshinori Murakami ${ }^{1,2}$, \\ Satoshi Tanimoto ${ }^{1,2}$, and Hidekazu Tanisawa ${ }^{1,3}$ \\ ${ }^{1}$ R\&D Partnership for Future Power Electronics Technology (FUPET), Japan \\ ${ }^{2}$ Nissan Motor Co., Ltd., 1-1, Morinosatoaoyama, Atsugi, 243-0123, Japan \\ ${ }^{3}$ Sanken Electric Co., Ltd., 3-6-3, Kitano, Niiza, Saitama, 352-8666, Japan \\ ${ }^{4}$ Fuji Electric Co., Ltd., Fuji-machi, Hino, Tokyo, 191-8502, Japan \\ ${ }^{a}$ kensuke-sasaki@aist.go.jp
}

Keywords: Three-Phase Inverter, All-SiC Inverter, Power Module, Output Power Density

\begin{abstract}
We, the R\&D Partnership for Future Power Electronics Technology (FUPET), have reported a forced-air-cooled $600 \mathrm{Vdc}$ three-phase $400 \mathrm{Vac}$ inverter built with SiC-JFETs and SiC-SBDs and designed to attain an output power density (OPD) of $40 \mathrm{~kW} / \mathrm{L}$ with a switching frequency $\left(\mathrm{f}_{\mathrm{SW}}\right)$ of 50 $\mathrm{kHz}$. This paper reports the test results of this inverter attaining an OPD of $40 \mathrm{~kW} / \mathrm{L}$ in operating a 3-phase motor with $\mathrm{f}_{\mathrm{SW}}=50 \mathrm{kHz}$, and an OPD of more than $60 \mathrm{~kW} / \mathrm{L}$ in operating an equivalent circuit with $\mathrm{f}_{\mathrm{SW}}=20 \mathrm{kHz}$ by adopting specialized high speed drive circuit boards.
\end{abstract}

\section{Introduction}

SiC-based semiconductor devices are expected to reduce losses as well as the size of power electronics applications like inverters or DC/DC converters taking advantage of their characteristic low resistance and high switching speed. In this paper, we demonstrate the OPD of the newly designed inverter [1] evaluated from a continuous switching test and actual loading test using a 3-phase induction motor.

\section{Specifications and Configuration}

An inverter unit having specifications and an appearance shown in Fig. 1 was fabricated. These JFETs and SBDs were selected because of the performance of low resistance as well as high reliability. Power modules integrated with heat sinks, dc link capacitors and cooling fans are included in the size of $250 \mathrm{cc}$. Controllers, sensors and gate drivers were excluded from the size. Ceramic capacitors $(100 \mathrm{nF})$ which were connected to the gate and source of JFETs were integrated in the power modules. This capacitor plays an important role in stabilizing the gate voltage of JFETs while the other arm is turning on [2].

\begin{tabular}{|l|l|}
\hline Input & DC600V \\
\hline Output & $3 \varphi-\mathrm{AC} 400 \mathrm{~V}$ \\
\hline Size & $107 \mathrm{~mm} \times 80 \mathrm{~mm} \times 33 \mathrm{~mm} \doteqdot 250 \mathrm{cc}$ \\
\hline FETs & $\begin{array}{l}\text { SJEC } 120 \mathrm{R} 025 \\
(1200 \mathrm{~V}, \quad \text { Rds }=25 \mathrm{~m} \Omega) \\
\text { ※SemiSouth }\end{array}$ \\
\hline Diodes & $\begin{array}{l}\text { SDC30S120 } \\
(1200 \mathrm{~V}, 30 \mathrm{~A}) \\
\text { ※SemiSouth }\end{array}$ \\
\hline
\end{tabular}

a) Specifications

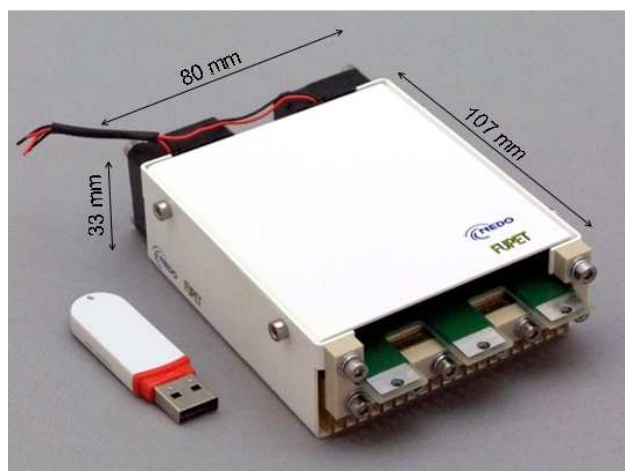

b) Inverter unit

Fig. 1: Specs and appearance of 3-phase inverter 
Configuration of the gate drive circuit and control unit is illustrated in Fig. 2. This gate drive circuit consists of two gate-driver ICs. One of these gate-driver ICs amplifies PWM signals isolated by the photo-coupler. Another amplifies a 200ns pulse signal during turn-on transition.

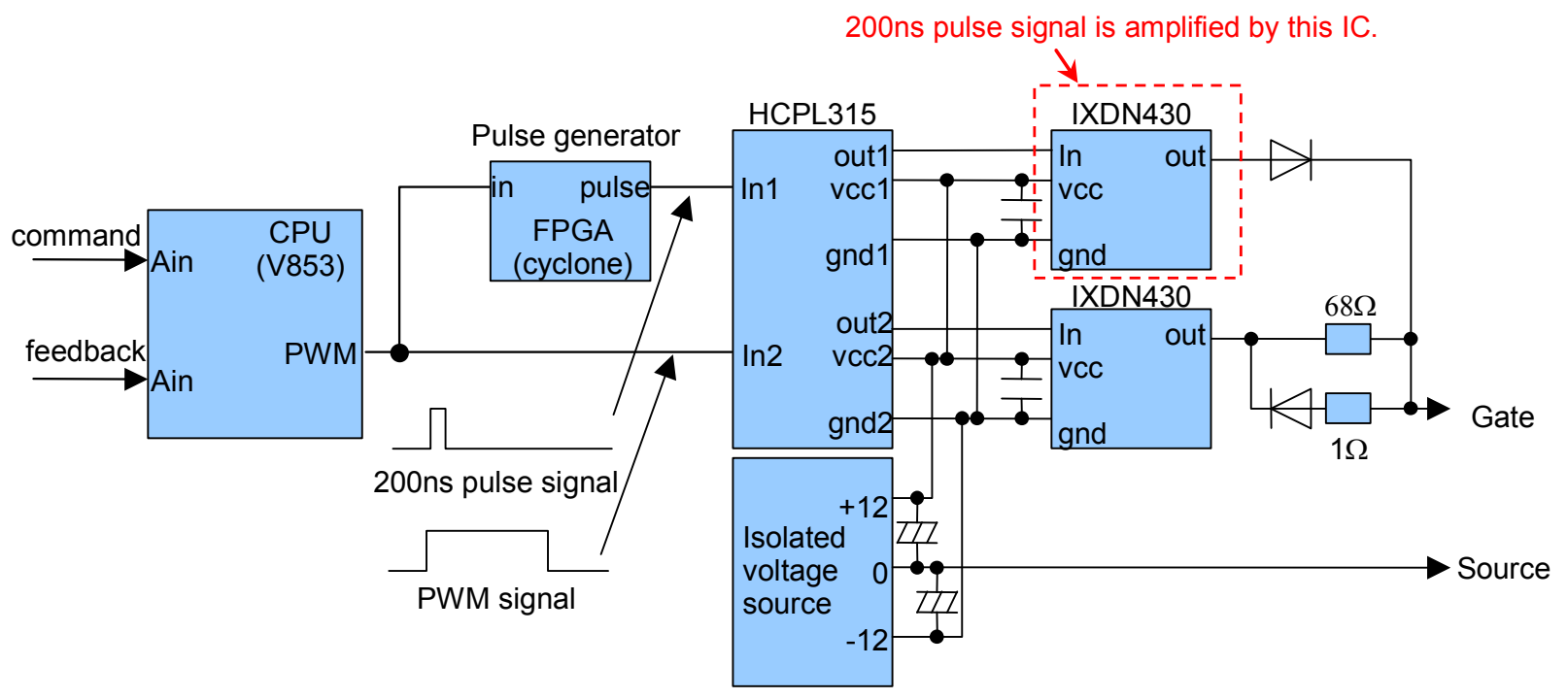

Fig. 2 : Configuration of gate drive circuit

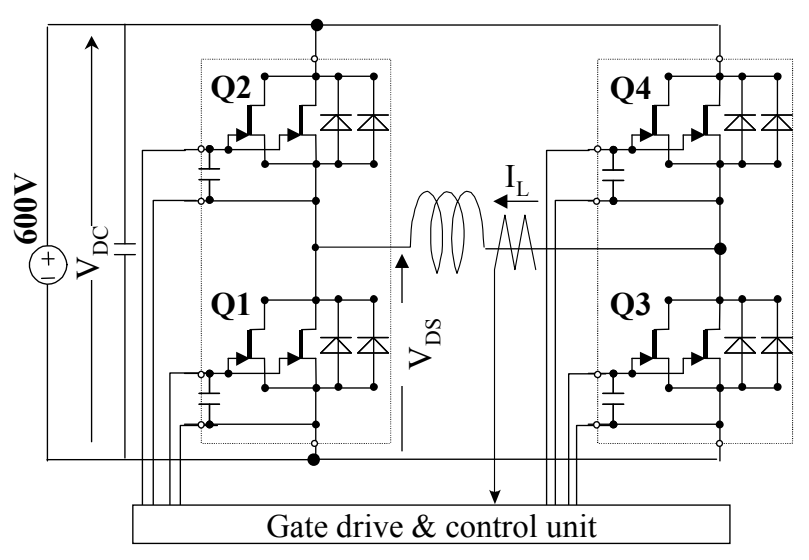

Fig. 3: Circuit of continuous switching test

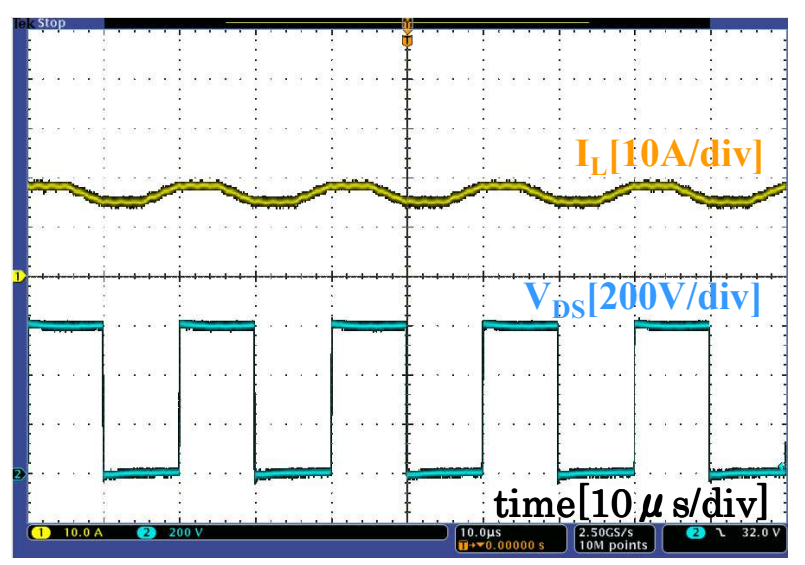

Fig. 4: Waveforms in continuous switching test

\section{Test results of continuous switching test}

The test circuit of the continuous switching test is shown in Fig. 3. Inductive load was connected to a pair of 2-in-1 power modules. Transistors Q1 and Q4 were operated by width controlled gate pulses having 90 -degree phase difference each other. The effective load current $\left(\mathrm{I}_{\mathrm{L}}\right)$ was kept a certain constant value by a feedback control. This test can simulate the same losses of a transistor as an operating actual load. We evaluated OPD of this inverter by using this test under several $\mathrm{f}_{\mathrm{SW}}$ and $\mathrm{I}_{\mathrm{L}}$ condition.

Fig. 4 shows an example of the switching waveforms of $V_{D S}$ and $I_{L}$ for a low-side switching block. The switching frequency was $50 \mathrm{kHz}$. The $\mathrm{I}_{\mathrm{L}}$ was 16.5 Arms, which was the same level of current stress for transistors as operating a $10 \mathrm{~kW} \mathrm{3-phase} \mathrm{induction} \mathrm{motor}$ under a power factor of 0.85 . In this test, the temperature of the power module saturated at $190{ }^{\circ} \mathrm{C}$. Temperature of power module was measured on heat sink. Because the heat resistance between heat sink and ambient is much higher than the heat resistance between devices and heat sink, device temperature becomes almost same as heat sink temperature. For this result, this inverter attained an OPD of $40 \mathrm{~kW} / \mathrm{L}$ at $\mathrm{f}_{\mathrm{SW}}=50 \mathrm{kHz}$. 
Fig. 5 shows the test results of module temperatures according to certain conditions of $\mathrm{f}_{\mathrm{SW}}$ and $\mathrm{I}_{\mathrm{L}}$. This inverter can attain an OPD of $60 \mathrm{~kW} / \mathrm{L}$ at $\mathrm{f}_{\mathrm{SW}}=20 \mathrm{kHz}$ with a module temperature of under $150{ }^{\circ} \mathrm{C}$. Even higher OPDs are expected at a power module temperature of over $200^{\circ} \mathrm{C}$.

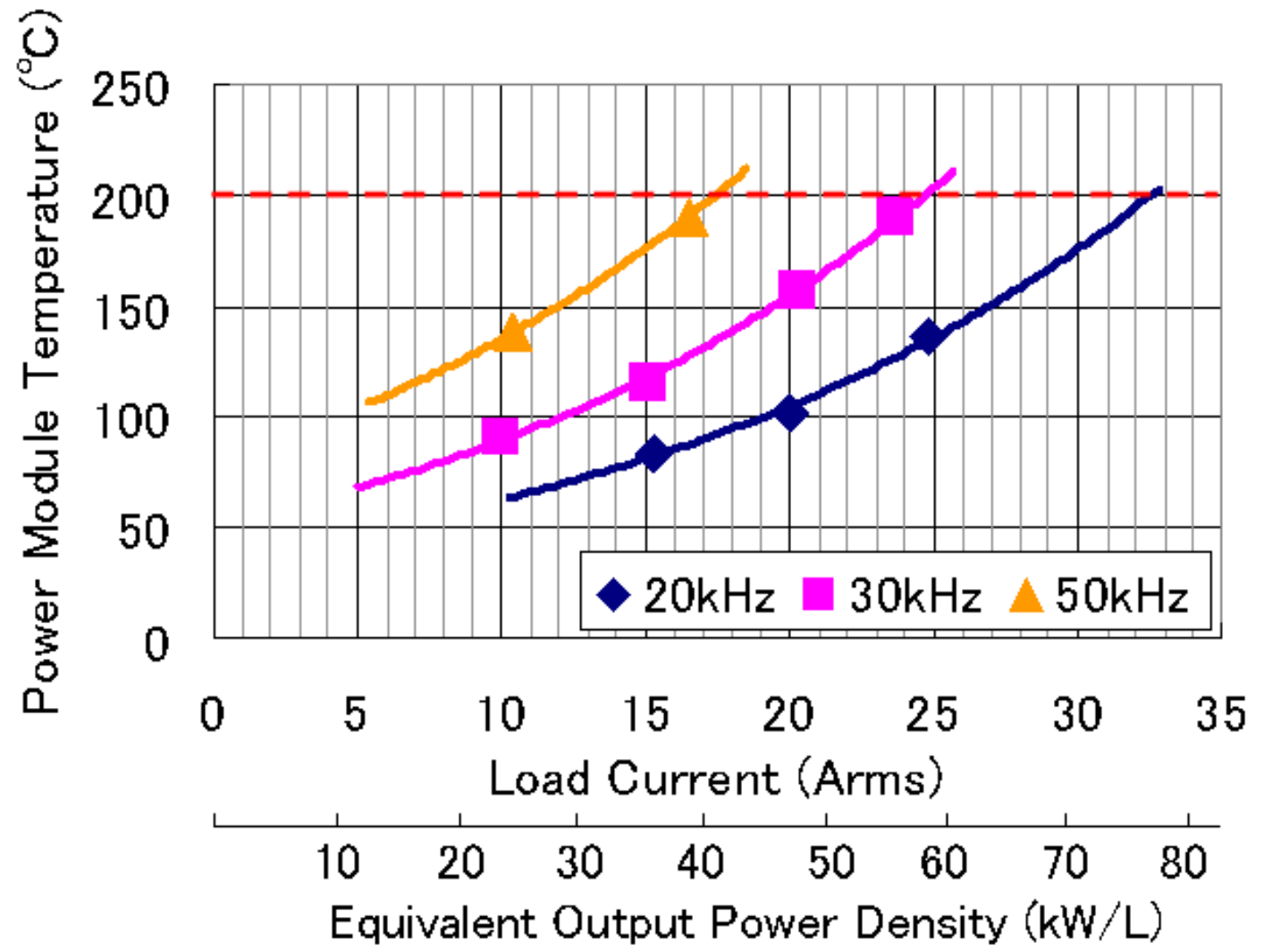

Fig. 5: Experimental result of continuous switching test

\section{Test result of operating 3-phase induction motor as an actual load}

Next, we evaluated whether this inverter could attain an OPD of $40 \mathrm{~kW} / \mathrm{L}$ in operating actual load. Fig. 6 shows the waveforms and conditions of operating a 3-phase motor test and indicates that this inverter can operate a 3 -phase motor of $10 \mathrm{~kW}$ stably at $\mathrm{f}_{\mathrm{SW}}=50 \mathrm{kHz}$. In this result, this inverter attained an OPD of $40 \mathrm{~kW} / \mathrm{L}$ at $\mathrm{f}_{\mathrm{SW}}=50 \mathrm{kHz}$ in operating actual load. In addition, the energy conversion efficiency here was $97.3 \%$.

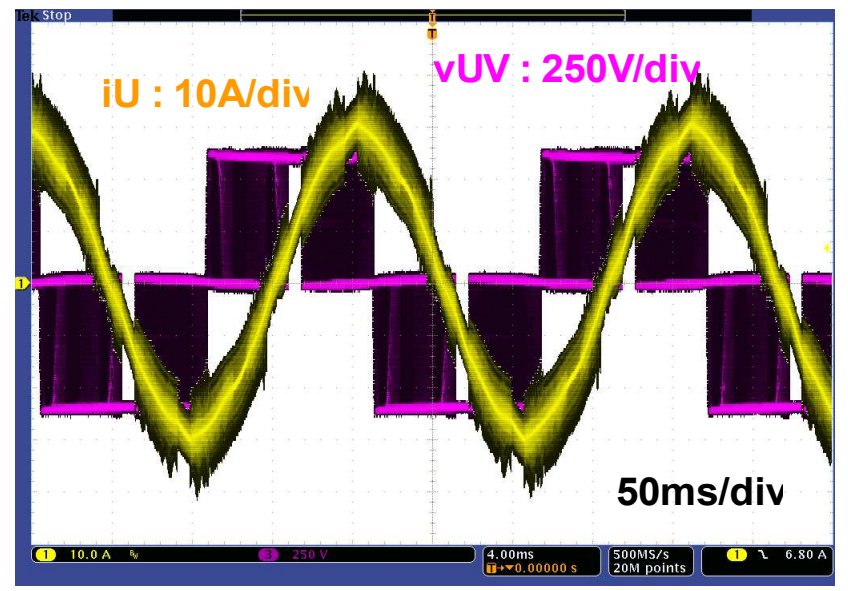

a) Operating waveforms

\begin{tabular}{|c|c|c|c|c|c|}
\hline $\begin{array}{l}\text { Input } \\
\text { voltage }\end{array}$ & 599.63 & $u$ & $\begin{array}{l}\text { Input } \\
\text { current }\end{array}$ & 17.438 & A \\
\hline $\begin{array}{l}\text { Input } \\
\text { power }\end{array}$ & 10.458 & w & & & \\
\hline Vrs & 405.66 & $u$ & Ir & 20.180 & A \\
\hline Vst & 405.21 & $u$ & Is & 19.534 & A \\
\hline Vtr & 405.76 & $u$ & $\begin{array}{l}\text { It } \\
\text { Output }\end{array}$ & 19.709 & A \\
\hline $\begin{array}{l}\text { Output } \\
\text { power }\end{array}$ & 10.177 & bit & frequency & 459.962 & He \\
\hline $\begin{array}{l}\text { Apparen } \\
\text { power }\end{array}$ & t 13.915 & KNG & $\begin{array}{l}\text { Reactive } \\
\text { power }\end{array}$ & 9.503 & hour \\
\hline Efficienc & $=y 97.31$ & $\%$ & $\begin{array}{l}\text { Power } \\
\text { factor }\end{array}$ & 0.7314 & \\
\hline
\end{tabular}

b) Operating conditions

Fig. 6: Experimental result for $10 \mathrm{~kW}$ induction motor as a load $(\mathrm{fsw}=50 \mathrm{kHz})$ 


\section{Summary}

A forced-air-cooled DC $600 \mathrm{~V}$ three-phase AC $400 \mathrm{~V}$ all-SiC inverter newly designed and fabricated has attained an OPD of $40 \mathrm{~kW} / \mathrm{L}$ with $\mathrm{f}_{\mathrm{SW}}=50 \mathrm{kHz}$ in operating actual AC motor. The efficiency was $97.3 \%$. Furthermore, an OPD of more than $60 \mathrm{~kW} / \mathrm{L}$ with $\mathrm{f}_{\mathrm{SW}}=20 \mathrm{kHz}$ in operating an equivalent circuit.

\section{Acknowledgement}

This work was supported by the Green IT Project directed by the New Energy and Industrial Technology Development Organization (NEDO) of Japan.

\section{References}

[1] Kohei Matsui, Yusuke Zushi, Yoshinori Murakami, Satoshi Tanimoto and Shinji Sato: A compact 5-nH one-phase-leg SiC power module for a 600V-60A-40W/cc inverter, The 2011 International Conference on Silicon Carbide and Related Materials (ICSCRM 2011), We-P-74

[2] Y. Zushi, S. Sato, K. Matsui, S. Tanimoto and Y. Murakami: Extend. Abst., IEEJ General Meeting (Mar. 16-18, 2011, Osaka) p. 251 (in Japanese) 